drug dependence on which young people are being continually hooked. At the same time more encouragement could well be given to research into the possibility of harmless smoking. Can it exist? A cigarette that gave the same or similar satisfaction as the tobacco-filled article but lacked its noxious effects would still be sociable and taxable. But it may prove to be a pipe dream.

1 Wynder, E. L., and Graham, E. A., Fournal of the American Medical Association, 1950, 143, 329.

Doll, R., and Hill, A. B., British Medical fournal, 1950, 2, 739.

3 Royal College of Physicians of London, Smoking and Health Now. London, Pitman 1971. Price 10s. net

- Royal College of Physicians of London, Smoking and Health. London, Pitman, 1962.

\section{Atypical Angina}

In $1959 \mathrm{M}$. Prinzmetal ${ }^{1}$ called attention to an unusual form of angina pectoris in which the pain occurred at rest but was not related to physical exercise or emotional stress. Though not nearly as common as angina of effort, it is not a rare syndrome, and it has the same age and sex distribution. The pain generally lasts longer than in effort angina, and it is usually more severe, while the attacks are frequently recurrent in a cyclical and regular pattern. Prinzmetal referred to this syndrome as a variant form of angina pectoris. $\mathrm{He}$ noted that if myocardial infarction occurred in a patient with variant angina the pain usually disappeared-unlike that of effort angina. The electrocardiographic changes also differ; instead of the generalized ST depression of classical angina in variant angina ST elevation is accompanied by reciprocal depression in the standard leads. The occurrence of ST depression without reciprocal elevation in classical angina is explained by the diffuse distribution of areas of myocardial ischaemia. In variant angina the extent of the ischaemia is restricted to a discrete area supplied by a large, narrowed coronary artery, ${ }^{2}$ and Prinzmetal postulated that the syndrome is due to an increase in vascular tone. Quite a modest increase in tone in such a vessel could lead to complete though temporary obstruction. Angiographic studies in six patients with variant angina have confirmed this explanation by showing a single stenotic lesion of one major vessel without significant disease elsewhere. ${ }^{3}$

The assumption that symptoms of variant angina are due to coronary spasm seems to contradict generally accepted concepts. Angina of effort develops only when there is severe myocardial hypoxia as a result of inadequate perfusion. In these circumstances the affected coronary vessels are already under the maximum physiological stimulus to dilate. This is probably true for classical angina, in which there is generalized disease of coronary vessels limiting their response to variations in tone and in which the ischaemic areas are scattered throughout the myocardiuin. Nevertheless, angina of effort as a result of myocardial hypoxia has been recorded in the absence of obstructive disease of visible coronary arteries. ${ }^{\text {4-6 }}$ More recently a remarkable case of variant angina has been reported in which myocardial hypoxia was confirmed despite the absence of any coronary artery disease demonstrable by angiography. ${ }^{7}$ In this patient the pain occurred at rest or during sleep, but not with exercise. Marked ST elevation was associated with the pain, and episodes of ventricular tachycardia and even ventricular fibrillation were recorded. After an episode of syncope due to complete heart block associated with pain a pace-maker was inserted. No abnormalities of haemoglobin-oxygen dissociation were found, and the basi for this patient's variant angina remained unexplained.

It is possible that in these patients vascular disease is present but not seen, for the state of the microcirculation cannot be assessed by angiography. This is, however, unlikely in view of reports of such patients who have died after infarcts with no apparent disease of the large or small coronary arteries at necropsy ${ }^{8}$ It is possible that myocardial ischaemia might arise from impaired oxygen diffusion or inappropriate oxygen utilization by the myocardial cells. Abnormalities in dissociation of oxygen from haemoglobin have been described in young women with angina and normal coronary angiograms. ${ }^{8}$ Furthermore, the energy needs of the myocardium may be abnormal. These are largely determined by the tension of the muscle wall of the ventricle, which is governed by the pressure within the cavity of the ventricle and the mean radius of the heart chamber. ${ }^{9}$ It has recently been suggested that the beneficial effect of nitroglycerine in angina is related to the reduction in ventricular volume and hence myocardial oxygen consumption associated with its use. ${ }^{10}$

The pathogenesis of angina is more complex than a mere obstruction to perfusion of the myocardium by atheromatous narrowing of the coronary arteries. The lack of correlation between the degree of atheroma and the presence of clinical disease suggested this many years ago. Vascular spasm, changes in the microcirculation, and physicochemical disturbance within the myocardium are certainly relevant, but their frequency and importance await further elucidation.

1 Prinzmetal, M., Kennamer, R., Merliss, R., Wada, T., and Bor, N., American fournal of Medicine, 1959, 27, 375.

2 Prinzmetal, M., Goldman, A., Shubin, H., Bor, N., and Wada, T. American Heart fournal, 1959, 57, 530.

3 MacAlpin, R. N., and Krattus, A. A., Circulation, 1967, 36, Suppl. No. 2 , p. 176

Neill, W. A., Kassebaum, D. G., and Judkins, M. P., New England Fournal of Medicine, 1968, 279, 789.

Kemp, H. G., Elliott, W. C., and Gorlin, R., Transaction of the Association of American Physicians, 1967, 80, 59.

Likoff, W., Segal, B. L., and Kasparian, H., New England fournal of Medicine, 1967, 276, 1063.

Whiting, R. B., Klein, M. D., Vander Veer, J., and Lown, B., New England fournal of Medicine, 1970, 282, 709.

Eliot, R. S., and Bratt, G., American fournal of Cardiology, 1969, 23, 633 Levine, H. J., and Wagman, R. J., American fournal of Cardiology, 1962, 9, 372.

Parker, J. O., Case, R. B., Khaja, F., Ledwich, J. R., and Armstrong, P. W., Circulation, 1970, 41, 593.

\section{Relapsing Polyneuropathy and Corticosteroids}

Though many cases of acute idiopathic polyneuritis, or the Guillain-Barré syndrome, have been reported, clearcut criteria for its diagnosis have proved difficult to define. In some patients the interval between the onset of symptoms and maximum neurological loss may be only a day, while in others apparently identical in every other way the interval may be several months.

G. Guillain, J. A. Barré, and A. Strohl ${ }^{1}$ divided their cases into those with a relatively acute onset and the atypical forms. L. D. Osler and A. D. Sidell ${ }^{2}$ suggested that the diagnosis should not be made when the interval exceeded two weeks. However, H. Ravn ${ }^{3}$ found that the interval had no effect on the later course of patients with this syndrome. The longest interval in his series of 127 patients was 45 days. Similarly, D. E. Pleasure and colleagues, ${ }^{4}$ accepting cases with an interval of up to two months, found no difference in prognosis between those with a shorter and those with a longer interval. When the symptoms progress for more than 
two months, fewer patients show the degree of recovery which is common in the Guillain-Barre syndrome, and it is probably best to set two months as the limit for diagnosis of it.

The syndrome is probably due to a cell-mediated autoimmune process - that is, an immunity reaction mediated by lymphocytes and allied cells. The evidence comes partly from work on animals ${ }^{5-7}$ and partly from the finding of lymphocytic infiltration in the nerves of patients within the first few days of the illness. ${ }^{8}$ Corticosteroid treatment has not given much benefit in the acute syndrome. An occasional patient may apparently improve dramatically, but for others, particularly those on respirators, the complications of high doses of corticosteroids may prove lethal. A multicentre trial is required to define the therapeutic place of these drugs.

Autoimmune activity seems to continue many years after recovery from the acute syndrome. Infiltration of the peripheral nerves by inflammatory cells has been noted, ${ }^{8}$ and lymphocytes sensitized to peripheral-nerve myelin have been found in the peripheral blood, ${ }^{9}$ though these cells sometimes disappear with clinical recovery. ${ }^{10}$ It is perhaps surprising, in view of this continuing activity, that relapses are so uncommon after acute idiopathic polyneuritis. ${ }^{11}$

A fluctuating neurological deficit, ${ }^{11}$ or occasionally a pattern of complete remissions and relapses, ${ }^{12} 13$ more frequently follows an attack lasting longer than two months than a shorter one. Some of these patients-and the percentage remains to be defined-respond dramatically to treatment with corticosteroids, though the dose may have to be higher than $60 \mathrm{mg}$ of prednisone or $80 \mathrm{IU}$ of corticotrophin per day. These patients may also show an equally dramatic relapse on reduction of the dose, often by quite a small amount. The best-documented example of this was a patient reported by J. H. Austin, ${ }^{12}$ with 20 relapses over five years related to variation in the dose of corticosteroids. Such patients are usually described as having a relapsing or recurrent polyneuropathy, though it is perhaps inappropriate to use this term when exacerbations are related to treatment.

W. B. Matthews and his colleagues ${ }^{14}$ have added a further three cases of chronic progressive neuropathy showing improvement with corticosteroid treatment and relapses on reduction of the dose. In their first case a gradually increasing dose of prednisone was required to hold the disease in check. In some remissions the patients became free of symptoms, but relapses were so profound as to lead to tetraplegia and respiratory embarrassment. At that time the patients were obviously worse than before the beginning of corticosteroid therapy. The authors rightly conclude that it is impossible to relate their clinical condition during such a relapse to what it would have been if corticosteroids had never been started, but they suggest that such a severe progression might not have been expected. Their unfortunate experience is not necessarily seen in all cases. Despite the dramatic sensitivity of these patients to slight reductions in dosage it is possible to treat effectually and even to cure some of them, eventually withdrawing the corticosteroid without producing a relapse.

Some patients with a chronic peripheral neuropathy may show no response to corticosteroids, while others may recover on treatment with them. The report by Matthews and his colleagues suggests that there is a third group who may initially improve but finally deteriorate. The proportion in each group is not at present known, and it seems impossible to forecast from the clinical features, including the level of protein in the cerebrospinal fluid, what the effect of treatment will be on an individual patient. But it is important to be aware of this third group in weighing the potential dangers of corticosteroid therapy against the present disability of the patient.

1 Guillain, G., Barré, J. A., and Strohl, A., Bulletin et Mémoires de la Société Médicale des Hôpitaux de Paris, 1916, 40, 1462.

2 Osler, L. D., and Sidell, A. D., New England fournal of Medicine, 1960, 262, 964.

3 Ravn, H., Acta Neurologica Scandinavica Suppl. No. 30, 1967, 43, 77.

Pleasure, D. E., Lovelace, R. E., and Duvoisin, R. C., Neurology (Minneapolis), 1968, 18, 1143.

5 Waksman, B. H., and Adams, R. D., fournal of Experimental Medicine, 1955, 102, 213.

Åström, K. E., Webster, H. de F., and Arnason, B. G., fournal of Experimental Medicine, 1968, 128, 469. Asbury, A. K., and Arneson, B. G., fournal of Neuropathology and
Experimental Neurology, 1968, 27, 581.

Asbury, A. J., Arneson, B. G., and Adams, R. D., Medicine, 1969, 48, 173.

9 Knowles, M., Saunders, M., Currie, S., Walton, J. N., and Field, E. J., Lancet, 1969, 2, 1168.

Cook, S. D., Dowling, P. C., and Whitaker, J. N., Archives of Neurology, $1970,22,470$.

11 Thomas, P. K., Lascelles, R. G., Hallpike, J. F., and Hewer, R. L., Brain, 1969, 92, 589.

12 Austin, J. H., Brain, 1958, 81, 157.

3 Ashworth, B., and Smyth, G. E., Acta Neurologica Scandinavica, 1969, 45, 342.

14 Matthews, W. B., Howell, D. A., and Hughes, R. C., fournal of Neurology Neurosurgery and Psychiatry, 1970, 33, 330.

\section{Disorders of the Distal Airways}

Acute bronchiolitis is a more dramatic illness in small children than in their elders. A rational basis for this clinical observation has now been provided by J. C. Hogg and colleagues, ${ }^{1}$ for they have shown that the diameters of distal airways remain constant from birth until about the age of 5 years and only then increase in size. It follows that infants have a higher peripheral airways resistance than older children and adults and thus a greater tendency to airways occlusion. In the absence during early life of an adequate system of collateral ventilation $^{2}$ from other alveovli this may lead to atelectasis and bronchiectasis.

The conducting airways of the adult lung progressively increase in total cross-sectional area at successive levels of branching. ${ }^{3}$ Distal airways as a whole should therefore offer less resistance to airflow than proximal ones, and this has been confirmed in animal experiments. ${ }^{4} 5$ This work suggests that conventional clinical and spirometric tests might be normal in adult patients despite narrowing of the distal airways. However, special techniques can detect disorders of function. For example, increased residual volumes attributed to premature closure of narrowed peripheral airways during expiration have been reported in bronchitic patients with relatively normal spirometric tests of ventilatory capacity. ${ }^{6}$ Abnormal distribution of ventilation and perfusion have also been found by means of radioactive xenon in patients with apparently mild chronic bronchitis. ${ }^{78}$ Recently G. Levine and colleagues ${ }^{9}$ examined groups of bronchitic and asthmatic patients in clinical remission and found that alveolar-arterial oxygen gradients and the ratios of physiological dead space to tidal volume were abnormally high. In a similar group of patients investigated by $\mathrm{A}$. J. Woolcock and colleagues ${ }^{10}$ dynamic compliance was reduced and "frequency-dependent;" that is, the lung was less distensible at fast than at slow respiratory rates because more time is needed during each breath to fill the alveoli supplied by a partially occluded airway.

The main practical conclusion to be drawn from these physiological studies is that narrowing of the smaller distal 